\title{
BMJ Open Senior ambulance officers in Swedish emergency medical services: a qualitative study of perceptions and experiences of a new management role in challenging incidents
}

Johan Hylander (1D , ${ }^{1}$ Britt-Inger Saveman, ${ }^{1,2}$ Ulf Björnstig, ${ }^{1}$ Lina Gyllencreutz ${ }^{1,2}$

To cite: Hylander J,

Saveman B-I, Björnstig U, et al. Senior ambulance officers in Swedish emergency medical services: a qualitative study of perceptions and experiences of a new management role in challenging incidents. BMJ Open 2020;10:e042072. doi:10.1136/ bmjopen-2020-042072

- Prepublication history for this paper is available online. To view these files, please visit the journal online (http://dx.doi. org/10.1136/bmjopen-2020042072).

Received 24 June 2020 Revised 19 November 2020 Accepted 23 November 2020

Check for updates

(C) Author(s) (or their employer(s)) 2020. Re-use permitted under CC BY-NC. No commercial re-use. See rights and permissions. Published by BMJ.

${ }^{1}$ Department of Surgical and Perioperative Sciences, Surgery, Umeå University, Umea, Sweden ${ }^{2}$ Department of Nursing, Umeå University, Umea, Sweden

Correspondence to Johan Hylander; johan.hylander@umu.se

\section{ABSTRACT}

Objectives Increased demands are placed on emergency services and their role and ability to act in incidents in challenging environments, for example, road tunnels. Collaboration between officers from emergency services (fire brigade, police and ambulance services) is important for an effective rescue effort. In Gothenburg, Sweden, a position as a senior ambulance officer (SAO) within the emergency medical services (EMS) has been introduced to support the regular force during major incidents. The aim of this paper was to explore the perceptions and experiences of the SAO's new management role in challenging incidents, such as those occurring in road tunnels.

Design A qualitative interview study.

Setting The study was carried out from February to June 2019 in Gothenburg, Sweden, which is a municipality with several road tunnels and a population of approximately 580000 people. SA0s collaborate with the corresponding function within the police and fire brigade, both having senior officers at major incident sites.

Participants Twelve SAOs.

Methods The study used semistructured interviews. The collected data were analysed using qualitative content analysis.

Results According to SAOs' experience, prehospital medical management included not only leadership, but also planning, training and indepth knowledge of, for example, tunnel environments. Furthermore, SAOs adopted an encouraging and teaching role for their colleagues. SA0s' responsibilities also included proactive planning together with the fire brigade and police, which was regarded as enhancing interorganisational collaboration. An overall theme emerged which the SAOs described as 'A new holistic approach to EMS leadership and management'.

Conclusions The participants considered that the new SAO role not only seems to improve the prehospital medical management, but also makes the EMS command structure during challenging incidents symmetrical with the fire brigade and police command structure. The implementation of national guidelines is desirable and is requested by the SAOs.
Strengths and limitations of this study

- A strength of the study is that the first author performed all individual interviews, making it easier to find the implicit meaning in the text.

Having more than one researcher decreased the risk of preunderstanding bias.

- By using a qualitative method, a deeper understanding of senior ambulance officers' experiences of their role during challenging incidents was reached.

- A possible limitation is the case characteristics of the study, which was carried out in a single city setting, which might impact the transferability of the results.

\section{INTRODUCTION}

In the event of a major incident (MI), increased demand is put on emergency services (ambulance, police and fire brigade) and on their competence regarding command and collaboration. ${ }^{2}$ An MI is an event that is so demanding that resources have to be organised, managed and used in a particular way. ${ }^{3}$ An MI includes situations where there are insufficient resources available to take care of all of the injured. ${ }^{4}$

In most countries, the senior police officer is the overall commander at the incident site. In Sweden, the three emergency service commanders have a common responsibility of managing an MI. ${ }^{5}$ However, the police and fire brigade have dedicated senior officers for managing MIs who have additional leadership training and experience in managing challenging situations. In comparison, the Swedish structure of emergency medical services (EMS) management seems rather flat. It has been indicated by others that in situations where they are expected to collaborate and coordinate with other emergency 
services officers, EMS personnel sometimes hesitate to take command when needed. ${ }^{78}$

EMS management and practice differs around the world. ${ }^{9}$ The Swedish system, that is, Prehospital Management Leadership (PML), a 2-day course that all Swedish EMS personnel attend, ${ }^{5}{ }^{10}$ is influenced by the Major Incident Medical Management and Support system, which is based on the following seven components: command/control, safety (self, scene, survivor), communication, assessment, triage, treatment and transport. ${ }^{1112}$ The PML system means that the personnel in the first arriving ambulance at the scene will assume the prehospital medical management, including roles such as the ambulance incident officer (AIO) and the medical incident officer (MIO), which have been shown to be challenging in many ways during an $\mathrm{MI}^{13}$ The MIO is the officer with the highest medical competence and is responsible for medical decisions regarding patient triage and treatment. The MIO should at least be a registered nurse. The AIO is responsible for communication and for coordination with other emergency services and for transportation. ${ }^{514}$

In Oslo, Norway, the EMS has introduced a senior position for prehospital medical management with the aim of being symmetrical to the other emergency services' senior officers. These officers have the authority to support or take over prehospital command from the first arriving ambulance. The Oslo strategy is to empower a few senior EMS officers who are specially trained in leadership and who have indepth knowledge of risk objects. In Oslo, knowledge about, for example, road tunnels, is seen as an important factor for a quick and competent response. ${ }^{6}$

If an MI occurs in a road tunnel, this puts extra demands on both the victims and the emergency services. This was what happened in the Oslofjord tunnel in Norway in 2011, where 32 road users were injured. ${ }^{15}$ Because the chance of survival of the severely and critically injured decreases over time, it is important for the EMS to access the victims as quickly as possible. However, the old EMS tradition to wait outside the tunnel for 'safety reasons' thus indicates a rather passive attitude. In other emergencies it is selfevident that an aggressive and quick response improves the chances of survival. ${ }^{16}$

In Sweden, there have not been any MIs in road tunnels. However, the crash of a Swedish coach in the Måbødal tunnel in Norway in 1988 which killed 16 people-of whom 12 were schoolchildren-sparked the development of the field of disaster medicine in Sweden. ${ }^{17}$ In addition, European Union legislation puts emphasis on the importance of being prepared for MIs in tunnels. ${ }^{18}$ The present study is part of a larger project focusing on the development of EMS responses to MIs in Swedish tunnels (personal communication, $2020 \mathrm{~A}$. Westman). It is therefore interesting to use incidents in tunnel environments as an example to gain more knowledge about prehospital emergency management. The Swedish prehospital management system is used in both minor and major incidents when the EMS is dispatched.
Therefore, experiences from minor incidents are also of value because the knowledge gained can be upgraded when an MI occurs.

In a few large cities in Sweden, similar strategies to those used in Norway have recently been initiated and are under development, with the purpose of improving prehospital medical management. Dedicated EMS personnel have been recruited to positions such as senior ambulance officers (SAOs), and the aim of the present study was to explore the perceptions and experiences of SAOs' new management role in challenging incidents, such as those occurring in tunnels.

\section{METHODS}

\section{Study design and context}

This qualitative interview study was conducted from February to June 2019 in Gothenburg, Sweden, a municipality with several road tunnels and a population of approximately 580000 people. ${ }^{19}$ Unfortunately, we did not find any official records of vehicle crashes in Swedish road tunnels and can therefore not comment on the total number of vehicle crashes during the study period. The function of SAO units was implemented in late 2018. These units are dispatched if one of the following criteria is met: three or more ambulances are dispatched to the same incident; there is collaboration with other emergency services, for example, in major traffic incidents; or there is a chemical, biological, radiological, nuclear or explosive incident. They may also be requested by the AIO on-site or if they are needed as a backup unit in the case of an increased threat level (eg, shootings). When not used for prehospital medical management missions, the SAO is included in the regular EMS organisation to assist other ambulances in the region with medical care. The SAO's vehicle has special command vehicle markings, has more communication equipment and has additional medical equipment for treating multiple casualties.

\section{Participants and data collection}

The inclusion criteria for informants were ambulance personnel employed as SAOs in the command and control units in Gothenburg. The study was approved by the station commander of the EMS in Gothenburg. Of 14 SAOs, 12 agreed to participate: eight were specialist nurses (registered nurses with 1-year specialisation in anaesthesiology or prehospital emergency care) and four were emergency medical technicians. Of the 12 SAOs, only one was female, and the SAOs had 6-25 years of work experience in EMS. Six interviews were conducted with two participants at a time at the participants' workplaces. The SAOs were working in pairs, and the interviews took place during working hours. The first author conducted all the interviews. A semistructured interview guide was developed for this study. First, the participants were asked if they had been involved in a tunnel incident, how they experienced the SAO function and how they experienced their role at an incident site. They were encouraged to 
think of a tunnel incident as a challenging example of what may happen. Thereafter, questions such as "How were joint decisions made in collaboration with other organisations' were asked. The interviews ranged from $55 \mathrm{~min}$ to $74 \mathrm{~min}$ and were recorded and transcribed verbatim.

\section{Ethical considerations}

This study was conducted in accordance with the Helsinki Declaration..$^{20}$ The participants were informed both in writing and orally regarding the aim of the study and the possibility to withdraw from the study at any time without giving a reason. Informed consent was obtained in writing from the participants. Participants' identities cannot be determined based on the quotes used in this study.

\section{Patient and public involvement}

There was no patient or public involvement in this study.

\section{Data analysis}

Data were analysed using qualitative content analysis. ${ }^{21}{ }^{22}$ The transcribed texts were thoroughly read to get an overview of the content. Meaning units were thereafter extracted and then labelled with codes, and similar codes were grouped into subcategories and categories. A theme was created to link the categories to a latent meaning. ${ }^{21}$ The analysis was discussed with the research group, and after reaching consensus five categories and one theme emerged. Quotations are used to show internal consistency.

\section{RESULTS}

The focus of the study's results is on the SAO's function and role. None of the participants had been dispatched to a major tunnel incident. The results are therefore mostly based on participants' perceptions of and experiences as SAOs during minor incidents, exemplified by road tunnel incidents with few injured persons. One theme emerged based on five categories (table 1).

\section{Theme: a new holistic approach to EMS leadership and management}

The theme covers the views of leadership and management as a whole, not just at the incident site. The SAOs described it as an eye-opening moment when they realised that the prehospital medical management included

\begin{tabular}{ll}
\hline Table 1 Theme and categories & \\
\hline Theme & Categories \\
\hline A new holistic approach to EMS & Leadership role \\
leadership and management & Encouraging role \\
& Knowledgeable role \\
& Proactive role \\
& Collaborative role \\
\hline
\end{tabular}

EMS, emergency medical services. not only leadership on-site, but also several other responsibilities. The holistic approach demands that the rescue effort is planned, trained for and carried out based on indepth knowledge of the tunnel environment. Furthermore, the SAOs adopted an encouraging leadership role regarding their own organisation and took an active part in collaborative forums with the fire brigade and police.

\section{Category 1: leadership role}

According to the participants, the prehospital medical management carried out by the AIO and MIO at incident sites was described as often being uncertain, passive, and in need of guidance and support from an SAO. The SAO role was therefore often to support the AIO and MIO on-site, and the participants perceived this as a way to improve the skills of AIO and MIO in prehospital medical management. However, their mandate as SAO was sometimes questioned by the AIO and MIO. It was also unclear when the SAO should take over responsibility for the prehospital medical management and when to provide support. They described this as an individual decision, and guidelines were asked for. Most commonly, they adopted a retracted approach and asked the AIO and MIO if they wanted to remain responsible for the prehospital medical management, which resulted in the SAO often playing a supporting role rather than taking over responsibility. To develop in their SAO role, the participants expressed a need for more extensive leadership training. On occasions when the SAO did not take over responsibility for the prehospital command at the incident site, the other emergency service officers sometimes became confused regarding who was responsible for the prehospital medical management.

We have a mandate but no markings (of the position or rank - author's remark), and this can be for better or worse. It is a bit complicated in comparison with the fire brigade that has different coloured helmets and vests. It is not all good, and it can get a bit confusing. (Participant 11)

\section{Category 2: encouraging role}

In their role as $\mathrm{SAO}$, the participants felt responsible for the EMS personnel's working environment, safety and well-being, especially after traumatic incidents. In their function as $\mathrm{SAO}$, the participants played an encouraging role because they thought that negative experiences could affect the EMS personnel's mental well-being as well as their ability to lead the response to future MIs. Therefore, the SAO's role made it possible for them to gather EMS personnel afterwards to evaluate and give feedback regardless of the personnel's level of experience.

The participants also felt that they had the responsibility of educating the EMS personnel. They described, for example, how they perceived the EMS personnel to be insecure regarding the use of EMS communication systems and that they needed more training. To improve both intraorganisational and interorganisational 
communication and collaboration, the SAOs also educated the EMS personnel in prehospital medical management as well as in communication.

It is important to have supportive conversations; I use them quite regularly when working as an SAO. It is also important to get feedback, for my own sake and for me to know how my colleagues are feeling. (Participant 6)

\section{Category 3: knowledgeable role}

The participants expressed a need for them, in their role as SAO, to have more indepth knowledge in order to increase their expertise. This might be possible by having specific allocated time to increase their knowledge in specific areas, for example, chemical spills and factors that could impact the safety of EMS.

When the participants gave examples from tunnels, the following risk factors were described: traffic flow, carbon monoxide levels, lack of proper working lights and loud traffic noise. For example, when getting a call to a tunnel incident involving a heavy goods vehicle, the SAOs use their indepth knowledge of risk factors to determine if the cargo could pose a threat to the EMS personnel on-site or to civilians. In their knowledgeable role, the SAOs expressed a need for better equipment for use in demanding conditions, for example, oxygen masks in a tunnel scenario involving smoke. They also expressed a need for carbon monoxide monitors and headphones or helmets with integrated communication systems.

Regarding protective equipment, especially in tunnel incidents, we need carbon monoxide monitors and we need oxygen level monitors... We need to measure the carbon monoxide levels before entering a tunnel. (Participant 1)

The knowledgeable role also included examples of tunnel architecture and traffic flow. The participants could use their SAO vehicle to block oncoming traffic, thereby lowering the risk for the EMS personnel. Further, knowledge of parking spots outside the tunnel makes it easier to decide on assembly points, thus increasing efficiency. Indepth knowledge also opened up for discussions about risk awareness. For example, vehicle incidents dealing with fires in e-vehicles in confined spaces such as tunnels caused some safety concerns as to whether responders' protective clothing would protect them from toxic battery fire smoke. The participants wished to have a joint learning platform to share knowledge and experiences of prehospital medical management within their own organisation as well as with the other emergency services.

Planning the rescue effort is very important. There is a significant difference between the EMS and fire brigade, which has more time for planning. We in the EMS need to be more active. I think an experienced-based database needs to be developed in collaboration with each other to create nationwide guidelines for conducting rescue efforts in challenging environments. (Participant 1)

\section{Category 4: proactive role}

The participants described the SAO role as proactive. For example, they participated in the planning of mass gathering events such as music events by trying to foresee potential hazards and planning operations appropriately. They also shared information with senior fire brigade and senior police officers to get a common picture of, as well as to handle, a potential incident. The participants expressed a need to allocate more time for incident planning, for example, time to tweak the fire brigade's response plans for tunnel incidents to better fit the EMS's needs.

A change in society's opinion of the emergency services has been observed by the participants; for example, the EMS are expected to show a more proactive attitude at the incident site. Such an attitude shows a discrepancy among participants because there is no consensus on how or even if the EMS should work in unsafe conditions. Some of the participants believed that working in unsafe conditions was an unnecessary risk for the EMS personnel, while others thought that unsafe working conditions were an implicit part of the job description.

In the role of SAO, a part of the job is to guide, distribute, and lead the EMS before we arrive at the incident scene. We have earlier been quite timid and waited for the fire brigade, but we can also be quite proactive and do a lot. (Participant 4)

\section{Category 5: collaborative role}

The SAOs met with their senior counterparts in the fire brigade and police every week to exchange knowledge and experiences. After these meetings, the SAOs felt that it was easier to contact the other senior officers at an incident site. By using the forum for dialogue and reflection, a sense of camaraderie and mutual understanding of their different organisations could be created.

We have started a project where we meet the local senior officers from the police and fire brigade once a week. We can discuss minor incidents and situations from the past week. It is a good forum for discussions. (Participant 12)

The participants desired a collaborative role in a forum not only with the fire brigade and the police, but also with the emergency dispatch centre (EDC) and the road traffic control centre (RTCC). The EDC was described as an important part for developing response plans, and the RTCC was described as important for sharing communication channels and implementing joint operational plans. They could, for example, relay information regarding risks and how the incident occurred to the SAO, who could use this information in planning the rescue effort. The RTCC also has access to safety vehicles 
with truck-mounted crash attenuators which are important for the EMS response. The participants mentioned that such a collaboration forum might increase the operational safety of the EMS personnel.

The vehicles with truck-mounted attenuators are usually early arrivals at the incident site, but sometimes it is hard to get hold of them because the fire brigade usually handles the communication with the RTCC. (Participant 9)

\section{DISCUSSION}

The theme 'A new holistic approach to EMS leadership and management' identified in this study shows a more holistic approach to leadership than what is usually described as prehospital medical management. ${ }^{5} 10$ The SAO function described in this study includes, in addition to the leadership role at the incident site, an encouraging role for the EMS personnel, a proactive role for preparedness for MIs, and a knowledgeable and collaborative role with the other emergency services' senior officers.

As the results show, SAO leadership at the incident site implies that SAOs either take over or support the role of the AIO and MIO. However, the results also show that the SAO leadership suffers from a lack of authority, and their leadership on-site is sometimes questioned by other ambulance personnel. The leader's ability depends on the necessary knowledge and skills in relation to the task at hand. ${ }^{23}$ As described in this study, there were no guidelines for when to support or to take over the leadership. Thus, the SAO's authority on-site needs to be further clarified. Moreover, to support the medical leadership at the incident site, a current initiative to improve the prehospital medical management of Swedish EMS is the introduction of an additional 2-day indepth course in PML (PML Plus) focusing on, for example, leadership skills and stress resistance. ${ }^{24}$ Those trained in PML Plus could have an increased mandate to support the personnel in the first arriving ambulance with prehospital medical management. ${ }^{24}$ However, this concept is not nationally adopted, and it is up to every regional council as to how and when this function should be used..$^{25}$ Thus, national guidelines for the SAO function may be developed regarding the SAO's mandate for prehospital medical management at an incident site.

As this study shows, the SAO function included an encouraging role, and the SAOs became a social support for EMS personnel, particularly during distressing incidents. Such social support is seen as protective against work-related stress. ${ }^{26-28}$ Social competence is desirable for good management, and abilities such as building trust, being a good listener, flexibility in communication and ability to interpret body language can create a supportive social environment. ${ }^{23}$ Thus, the SAO initiative to support EMS personnel on a regular basis might decrease the risk of burn-out and post-traumatic stress symptoms and thus contribute to a healthy work environment.
This study also shows a need for the SAO to have extended knowledge of, for example, tunnel structures as well as special tunnel safety issues such as how to handle chemical spills and traffic flow. However, lack of time to develop response plans and guidelines affects the SAO's indepth knowledge about risk objects and consequently the possibility to prepare and train other EMS personnel. Others have described how the SAO needs to have necessary knowledge and skills in relation to the task at hand in order to be able to manage the EMS personnel during major and minor incidents that require collaboration and coordination with other emergency services. ${ }^{23}$ Thus, more allocated time for incident planning and for gaining indepth knowledge is needed.

As our results show, the EMS are expected to show a more active attitude at incident sites in tunnels. However, with such an attitude, the SAOs were concerned about their own and the EMS personnel's safety. Safety issues in extreme environments have been raised by EMS personnel in other contexts. ${ }^{8930}$ According to the senior function for prehospital medical management developed in Oslo, the EMS shows a more active attitude and uses the policy of 'safe enough' instead of 'entirely safe'. ${ }^{6}$ The 'safe enough' policy might be a new approach for some, and more research, and perhaps even new legislation, is needed before there can be a change in attitude within the Swedish EMS.

The participants expressed that mutual trust was built by using a collaborative forum between the senior officers from the different emergency organisations. This is in line with experiences from Oslo showing that mutual trust improves on-site collaboration. ${ }^{6}$ Others have also shown that it is beneficial to have a pre-existing bond between the emergency services officers before managing an emergency together. ${ }^{31}$ In this study, other collaborative organisations, such as the RTCC, were asked to be included in the collaboration forum because this was perceived to improve on-site collaboration. These kinds of locally created forums might also serve as models for other regional emergency services.

\section{Methodological considerations}

This study is based on interviews with 12 out of a total of 14 SAOs in one major city in Sweden. Therefore, it is limited to this setting, but might be transferable to similar settings and conditions. It is also up to the reader to judge the external validity of this paper. To facilitate this, the analysis process and selection of participants have been described. ${ }^{22}$ The interviews were rich with descriptions, and the analyses were in accordance with the method of qualitative content analysis. ${ }^{21}$ Two of the authors are familiar with and have experiences as providers of EMS care, which led to an understanding of the context. However, their preunderstanding could also be a potential source of bias in interpreting the results. To counteract this, the other two authors also analysed the text, and the categories and theme were discussed until consensus was reached between all authors. 


\section{CONCLUSION}

The participants considered that the SAO role not only seems to improve the prehospital medical management, but also makes the EMS command structure in incidents that require collaboration symmetrical with the fire brigade and police command structure. National implementation of guidelines is desirable and is requested by the SAOs.

Acknowledgements The authors would like to thank the participants for contributing to this study. The authors would also like to thank Johanna Björnstig at the Centre for Research and Development in Disaster Medicine, Umeå University, for transcription of the interview data.

Contributors JH: planning the study, data collection, data analysis and writing of the manuscript. B-IS: supervision, planning the study, data analysis and writing of the manuscript. UB, LG: planning the study, data analysis and writing of the manuscript. All authors have read and approved the final manuscript.

Funding This work was supported by the Swedish National Board of Health and Welfare.

Competing interests None declared.

Patient and public involvement Patients and/or the public were not involved in the design, or conduct, or reporting, or dissemination plans of this research.

Patient consent for publication Not required.

Ethics approval The study was approved by the Swedish Ethical Review Authority (2019-03611).

Provenance and peer review Not commissioned; externally peer reviewed.

Data availability statement Data are not available. As it is in swedish and we need to maintain confidentiality to the participants.

Open access This is an open access article distributed in accordance with the Creative Commons Attribution Non Commercial (CC BY-NC 4.0) license, which permits others to distribute, remix, adapt, build upon this work non-commercially, and license their derivative works on different terms, provided the original work is properly cited, appropriate credit is given, any changes made indicated, and the use is non-commercial. See: http://creativecommons.org/licenses/by-nc/4.0/.

ORCID iD

Johan Hylander http://orcid.org/0000-0003-1346-7200

\section{REFERENCES}

1 Carron P-N, Reigner P, Vallotton L, et al. Implementation of a medical command and control team in Switzerland. Disasters 2014;38:434-50.

2 Accident Investigation Board Norway. Report of fire in a truck on E16 in the Gudvangatunnel in Aurland 5 August 2013. (Norwegian). Lillestrøm: SHT, 2015. Available: https://www.aibn.no/Veitrafikk/ Avgitte-rapporter/2015-02?lcid=1033\&waf_client=desktop [Accessed 4 Jun 2020].

3 Swedish National Board of Health and Welfare. Results of the referral procedure of concepts in disaster medicine (swe DNR 4.510601/2018. Swedish national Board of Health and Welfare, 2018.

4 Lennqvist S. Disaster medicine - definitions and objectives (swe). 3rd. Stockholm: Liber, 2009: 11-18. ISBN: 978-91-47-08481-4.

5 Rüter A, Nilsson H, Vikström T. Medical Command and Control at Incidents and Disaster - From the Scene to the Hospital Ward. Lund: Studentlitteratur, 2006

6 Hylander J, Saveman B-I, Björnstig U, et al. Prehospital management provided by medical on-scene commanders in tunnel incidents in Oslo, Norway - an interview study. Scand J Trauma Resusc Emerg Med 2019;27:78.

7 Berlin JM, Carlström ED. Collaboration Exercises-The lack of collaborative benefits. Int J Disaster Risk Sci 2014:5:192-205.

8 Aléx J, Lundin H, Joansson C, et al. Preparedness of Swedish EMS personnel for major incidents in underground mines. Glob $\mathrm{J}$ Health Sci 2017;5:239-43.
9 Cooper A. Healthcare Incident Management Systems. In: Reilly MK, Markenson DS, eds. Health care emergency management: principles and practice. Sudbury, MA: Jones \& Bartlett Learning, 2010: 21-45.

10 Rüter A, Nilsson H, Wikström T. Prehospital Management - A certified concept education. Scand J Trauma Resusc Emerg Med 2004;12:148-9.

11 Nilsson H. Demand for Rapid and Accurate Regional Medical Response at Major Incidents [dissertation. Linköping University, 2013.

12 Advanced Life Support Group. Major Incident Medical Management and Support. In: The practical approach at the scene. 2nd ed. London, UK: BMJ Books, 2002.

13 Hardy S, Fattah S, Wisborg T, et al. Systematic reporting to improve the emergency medical response to major incidents: a pilot study. BMC Emerg Med 2018;18:4.

14 Advanced Life Support Group. MIMMS - in Swedish: major incident medical management and support: practical management of healthcare in the event of a major incident. 2 nd ed. Lund: Studentlitteratur, 2014

15 Accident Investigation Board Norway. Report of fire in a truck on RV 23 in the Oslofjordtunnel, 23 June 2011. (Norwegian). Lillestrøm: SHT, 2013. Available: https://www.aibn.no/Road-Traffic/Reports/ 2013-05 [Accessed 18 May 2020].

16 Meizoso JP, Valle EJ, Allen CJ, et al. Decreased mortality after prehospital interventions in severely injured trauma patients. $J$ Trauma Acute Care Surg 2015;79:227-31.

17 Swedish Accident and Investigation Board. Rapport O 1992:2 bus crash 1988-08-15 Måbødalen, Norge. (Swedish). Stockholm, 1992. Available: https://www.havkom.se/assets/reports/O-1992-02Bussolycka-Måbödalen-kompr.pdf [Accessed 4 Jun 2020].

18 EUR-Lex. Directive 2004/54/EC of the European Parliament and of the Council of 29 April 2004 on minimum safety requirements for tunnels in the trans-European road network. OJEU 2004:167.

19 Statistics Sweden. 50 largest municipalities, by population. Stockholm, 2020. Available: https://www.scb.se/en/finding-statistics/ statistics-by-subject-area/population/population-composition/ population-statistics/pong/tables-and-graphs/rank-listsmunicipalities/swedens-50-largest-municipalities-2019/ [Accessed 4 Jun 2020].

20 World Medical Association. World Medical association Declaration of Helsinki - ethical principles for medical research involving human subjects, 2013: 29-32.

21 Graneheim UH, Lundman B. Qualitative content analysis in nursing research: concepts, procedures and measures to achieve trustworthiness. Nurse Educ Today 2004:24:105-12.

22 Graneheim UH, Lindgren B-M, Lundman B. Methodological challenges in qualitative content analysis: a discussion paper. Nurse Educ Today 2017;56:29-34.

23 Larsson G, Carlstedt L, Andersson J, et al. A comprehensive system for leader evaluation and development. Leadership \& Org Development J 2003;24:16-25.

24 Katastrofmedicinskt centrum. PS Plus [Internet]. Linköping: Katastrofmedicinskt centrum, 2017. Available: https://www. psconcept.se/om-ps-plus [Accessed 22 Apr 2020].

25 Nilsson H, Kristiansson T. Disaster medicine preparedness: to manage healthcare in a particular way. (Swedish. Lund, Sweden: Studentlitteratur AB, 2015.

26 Brooks SK, Dunn R, Amlôt R, et al. Social and occupational factors associated with psychological distress and disorder among disaster responders: a systematic review. BMC Psychol 2016;4:18.

27 Sterud T, Ekeberg Øivind, Hem E. Health status in the ambulance services: a systematic review. BMC Health Serv Res 2006;6:82:1-10.

28 Oliveira A, Neto F, Teixeira F, et al. Working in prehospital emergency contexts: stress, coping and support from the perspective of ambulance personnel. Int J Workplace Health Manag 2019;12:469-82.

29 Karlsson S, Saveman BI, Gyllencreutz L. The medical perspective on mining incidents: interviews with emergency medical service (EMS) personnel. IJES 2019;8:236-46.

30 Doohan IS, Saveman BI, Gyllencreutz L. Limited medical perspective at a strategic level in relation to mass casualty incidents in Swedish tunnels. IJEM 2019;15:360-74.

31 Grunwald JA, Bearman C. Identifying and resolving coordinated decision making breakdowns in emergency management. IJEM 2017;13:68-86. 